good the care is. The supported lodgings scheme produces two different forms of accommodation: (a) family care, and (b) hostel-like - both are greatly needed in many districts.

A supported lodgings scheme can release patients for other needs, or to overcome crowding in the wards. A consultant with special responsibility for rehabilitation is particularly helped by such a scheme and it should be an essential part of a rehabilitation department in any traditional psychiatric hospital or district general hospital.

In Gloucestershire the Department of Health and Social Security pay $£ 50-£ 65$ per week to the landladies and landlords. All patients are in receipt of invalidity benefit or noncontributory invalidity benefit, so variable amounts are payable and every case is assessed by this section of the Department of Health and Social Security. This amount does not fully cover the cost of the supported lodgings, so the remainder of the lodgings fee, plus the patient's money, comes from supplementary benefit, if the patient's personal savings are below $£ 3,000$.

The supported lodgings officer's post is funded by the Gloucestershire Association for Mental Health and the Gloucestershire Social Services Department and is at present part-time, but is to become full-time soon.

During the first 15 months of the Gloucestershire scheme, 75 patients were discharged. A similar scheme started in Salisbury in January 1974 discharged within three years 90 patients, and at six years, 125 . With experience of supported lodgings schemes for nearly 10 years now. I am sure a supervised lodgings scheme allows many patients to be discharged from hospital who could not cope in group homes or bed-sits. The 'new long-stay' can often be discharged by this means as well as the 'old long-stay'. It is also helpful with some 'short-stay' patients. The mentally handicapped are well known to be helped by such a scheme.

A well organized and supervised supported lodgings scheme is invaluable - why is it not used more often?

B. H. ANSTEE

Coney Hill Hospital

Coney Hill, Gloucester

\section{Single-handed consultant practice in psychiatry DeAr SIR}

In the practice of psychiatry, especially mental handicap and the psychiatry of old age, there are many consultant psychiatrists who work single-handed. That is, they work in Health Districts and hospitals where there is no colleague with whom they can share duties, responsibilities and problems.

Occasionally single-handed posts are the first in a developing service. Sometimes the case load of a subspecialty may warrant only one consultant. Often, for example in mental handicap, the consultant psychiatrist works single-handed because posts are vacant as a result of consultants retiring and the Health Authorities failing to fill the posts.

Single-handed practice has many disadvantages. Such a consultant is on call almost the whole time and even if the demands and calls out of working hours are infrequent, he must remain accessible which places restriction on his social and professional life. If he has responsibility for large numbers of in-patients he is more restricted in this respect than a colleague in a sub-specialty with few in-patients. He will also be more likely to be working without the help of registrars or senior registrars. Because of difficulty obtaining locum cover and persuading other psychiatrists to provide cover, he is unable to arrange annual and study leave as easily as consultants working with colleagues. He is also less able to have time off to attend meetings which involve travel. There are also the risks of isolation and overcommitment with the possible impairment of mental and physical health with consequent risks to patients and the service.

Often where a single-handed consultant is operating a service apparently satisfactorily there is no incentive for Health Authorities to fill vacant posts which would provide him with a colleague. The Authority can procrastinate, save on salaries and contend that the service can manage with fewer consultants anyway.

What are the possible medico-legal implications for a single-handed consultant if something goes wrong? Where he is covering a service which should have two or three consultants to provide it, he is trying to do the impossible and to blame him for this would seem unreasonable. Perhaps a consultant in such a position should inform the employing authority of the limitations the inadequacy of staff must impose.

Single-handed consultant practice appears to have no advantages and can be unfair to doctor and patient. In long periods during which consultant posts are unfilled it should not be beyond the capacity of Regional Health Authorities to arrange, at a supra-district level, for single-handed consultants to be 'paired' with others in the same specialty. The single-handed consultant receives sympathy but little practical help. He becomes a willing slave to try to offer a service which he appreciates cannot be as good as in a fully staffed organization. From all points of view single-handed consultant psychiatric practice deserves scrutiny by professional bodies.

\section{Meanwood Park Hospital \\ Leeds}

D. A. SPENCER

\section{Dear Sir}

\section{Psychopaths in Special Hospitals}

May I compliment Dr Mawson on his well argued article, 'Psychopaths in Special Hospitals' (Bulletin, October 1983, 7, 178-81). 
The 'fly in the ointment' has been the apparent reluctance of the Home Office to sanction expeditious return of a patient to prison following hospital treatment or when it has become clear that treatment is ineffective. I have experience of such transactions taking many months to negotiate during which time other patients are deprived of the opportunity of treatment.

This is the situation which obtained under Section 72 (MHA, 1959) at a general psychiatric hospital. If the matter has now changed I am sure that there are many psychiatrists who will be most happy to hear of it.

Moorhaven Hospital

Alan Poole

Ivybridge, S. Devon

\section{DeAr Sir}

\section{Facilities at 17 Belgrave Square}

Dr Snaith raises some interesting points about the facilities available to members when they visit the College (Bulletin, February 1984, 8, 28-9).

I should like to take this opportunity to advertise the fact that there is a pleasant sitting room here, for the use of members, situated immediately to the left after you come in through the front door. It seems that Dr Snaith did not know about this, although it has been mentioned in the Bulletin, and it may be that others are also unaware of it.

I will look into the other deficiencies that Dr Snaith highlights and see to what extent they can be rectified.

R. G. PrIest Registrar

17 Belgrave Square

London SWI

\section{More papers on administrative aspects of psychiatry}

DeAr Sir

Part of a psychiatrist's duties are clearly administrative, yet there seems to be a great shortage of papers on the administrative aspects of psychiatry, both in the Journal and the Bulletin. For example, someone could use systems theory to look at the operational functioning and patterns of communication in various institutions.

Midland Nerve Hospital

Edgbaston, Birmingham

R. M. BIRKETT

\section{The College and the British Psychological} Society

DeAR Sir

This is as good a time as any to remind psychiatrist and psychologist colleagues of the existence of this Joint Standing Committee which was set up in 1977 to consider, on behalf of the parent bodies, matters of concern to both. The Committee meets three times annually, under a Chairman elected in turn from the psychiatrist and psychologist members. The current membership is as follows: Chairman: Dr F. M. McPherson (BPS); Vice-Chairman: Dr J. L. T. Birley; College Members: Professor T. Arie, Dr J. Pedder, Dr W. Lumsden-Walker, Dr M. MacCulloch and $\operatorname{Dr} \mathbf{K}$. Day; BPS Members: Mr D. A. Black, Mr M. K. Cornwall, Dr F. N. Watts, and Mr R.P. Webster. The meetings are also attended by Dr A. Sippert (Principal Medical Officer, DHSS), Dr E. Miller (Consultant Adviser in Clinical Psychology, DHSS) and Dr C. V. Newman (Scientific and Professional Adviser, BPS).

Among the topics which the Committee has considered recently have been the Statutory Registration both of psychotherapists and of psychologists, the Mental Health (Amendment) Act and the Mental Health Commission, the teaching of psychology to trainees in psychiatry, and the obtaining of experience of educational psychology for trainees in child psychiatry. In addition, joint conferences are being planned by the Committee for 1984, one between the Child and Adolescent Psychiatry Section and the Division of Child and Educational Psychology, with participation also by the Division of Clinical Psychology, and the other a larger meeting between the College and the BPS which may concentrate on general educational issues, the interrelationship of the professions, and the clinical priorities of NHS clinical psychology.

Most topics are brought to the Committee by the relevant sub-system of the parent bodies to which it reports back. Inevitably, therefore, the Committee is not often very visible to the individual members of the College or the BPS. However, the Committee would welcome suggestions from members of topics of relevance to both professions which could profitably be considered by the Committee. Any such suggestions should be sent to the Administrative Secretary of the Joint Standing Committee at the College address.

Royal Dundee Liff Hospital

Frank M. McPherson

Dundee

\section{Miss Natalie Cobbing}

A Memorial Service has been arranged and will take place on Thursday, 29 March, 1984 at 12 noon at St. Paul's Church, Wilton Place, London S.W.1. 